\title{
Knowledge and the Knowledge Gap: Time to Reconceptualize the "Content"
}

\author{
Leo W. Jeffres, David Atkin* and Hanlong Fu
}

Communication, University of Connecticut, Storrs, CT 06268, USA

\begin{abstract}
The knowledge gap perspective is a seminal theory of mass communication effects, one that bears wider consideration in the information sciences literature, particularly as converging voice, video and data channels continue to converge and deliver each other's services. Although largely rooted in studies of traditional news media during the postmodern era, these gaps in audience information help define the digital divides accompanying the diffusion of new media channels. Given that over a hundred studies have investigated the knowledge gap —including several meta-analyses (e.g., Gaziano, 1996; Hwang \& Jeong, 2009)--the present study provides further conceptual explication via a narrative review of the knowledge gap literature. Yet the knowledge gap may prove to be an important theory describing current phenomena if we apply it in an environment where media have been transformed dramatically, where individual choice and control have increased greatly, and generational differences have become more pronounced. After providing a taxonomy of the different contexts in which knowledge gaps can be explicated, the essay concludes with an argument for moving beyond the "relativistic" arguments and considering how the concepts and the theory may be useful in describing reality today.
\end{abstract}

Keywords: Knowledge, knowledge gap, reconceptualize, relativistic.

\section{INTRODUCTION}

The knowledge gap perspective (Tichenor, Donohue, \& Olien, 1970) stands as one of the penitential theories in communication. Although largely rooted in studies of traditional news media during the postmodern era, as media convergence continues, these gaps in audience information now apply to online media outlets ${ }^{1}$. Since traditional mass entertainment and information media are increasingly coming through the same channels, it's useful to consider conventional knowledge dynamics in the new media environment.

The knowledge gap perspective provides a compelling vehicle for understanding cognitive effects of media through a theoretical framework that can accommodate traditional one-way mass media as well as two-way telematic systems. This paper argues that by applying theory and by considering mass media and information services as a whole--instead of atomized industries--we can and deepen our understanding of knowledge acquisition in the age of digital media. This process of theoretical explication can be better understood in the context of a wider taxonomy of what's being conveyed via the media and to what effect.

When Phil Tichenor and his colleagues developed the "knowledge gap," they unleashed a movement in communication research, one that has generally focused on the political arena. But this tradition has also examined individual differences, how the context affects this phenomenon and

*Address correspondence to this author at the Department of Communication Science, University of Connecticut, Storrs, CT 06268, USA; Tel: 860-486-3090; Fax: 860-486-5422;

E-mails: david.atkin@uconn.edu; djatkiunmail@yahoo.com how audiences process media messages (Tichenor et al., 1970; Donohue, Tichenor, \& Olien, 1973a, 1973b, 1975).

Since political activity and public affairs are so important to a democracy, it's no surprise that communication research has paid the greatest attention to how the public acquires information about elections (e.g., Eveland \& Scheufele, 2000; Holbrook, 2002; Hwang \& Jeong, 2009; Kwak, 1999; Lee \& Cappella, 2001; Liu \& Eveland, 2005; McCann \& Lawson, 2006; Meirick \& Wackman, 2004; Weaver \& Drew, 2001) or information (Weenig \& Midden, 1997) campaigns, public programs (Rucinski, 2004) or government activities in general. Given that the bulk of the knowledge gap research has been conducted by scholars in mass communication, particularly journalism, we have also given greater weight to the news media and how people learn about public affairs (e.g., Genova \& Greenberg, 1979; Rhine, Bennett, \& Flickinger, 2001; Valente \& Saba, 2001) and issues in the media such as health (e.g., Gallagher, 2007; Niederdeppe, 2008), the fodder of newspapers and nightly newscasts. The media populating our hearths have changed considerably, along with the contexts governing their use (e.g., Lin \& Atkin, 2007). But that's not the key issue of interest here, so we put it aside until later.

\section{THE KNOWLEDGE GAP: DEFINING KNOWLEDGE}

Tichenor and his colleagues (1970), in their introductory article about the knowledge gap, cited time trend data for not only knowledge but also for "stated beliefs" (when man would reach the moon) and the relationship between education and understanding. Shortly thereafter, they made a distinction between "knowledge of" rather than "knowledge about" something, with the former referring to familiarity with a topic or events surrounding it and the latter referring 
to analytic and formal knowledge (Donohue, Tichenor \& Olien, 1973).

A series of studies over a period of a couple decades focused on local issues, with an emphasis on environmental issues but also local development. A 1975 report on data from several studies focused on local issues dealing with the environment (e.g., logging, river pollution) or political regionalization. Knowledge was measured with open ended questions asking respondents to report what they had heard about an issue, and responses were judged for the number of accurate statements made (Donohue, Tichenor, \& Olien, 1975). The same methodology was followed in additional studies a decade later (Tichenor, Olien, \& Donohue, 1987), where the issues were a high-voltage power line, nuclear power plant safety problems, a downtown street renewal project, and a heat fuel assistance program for needy families $^{2}$.

At a recent conference where Tichenor was honored--one of many sessions focused on these concepts--participants engaged in a discussion over the central concept of the "knowledge gap," knowledge itself. Scholars focusing on science communication and science journalism note that scientific facts, or knowledge, about such controversial subjects as global warming are quite relative, dependent on the state of science at a point in time and changeable down the road with subsequent research. This is also consistent with the definition of science as a process of discovery, where empirical evidence rejects rather than confirms for all time what we "know." Surely these points are found in lectures of our research methods classes in communication. If "knowledge" is "forever" relative, then the primary gap of concern is between "beliefs" (about what we know) rather than knowledge.

This brings us to the thesis being argued here: we need to conceptualize "knowledge" and what it "should" mean if we are to advance our understanding of these basic processes underlying the "knowledge gap" and the public's acquisition of knowledge, news, information, the content of media and interpersonal messages. Given that over a hundred studies have investigated the knowledge gap-including several meta-analyses (e.g., Gaziano, 1996; Hwang \& Jeong, 2009)-the present study provides further conceptual explication via a narrative review of the knowledge gap literature.

\section{EXPLICATING KNOWLEDGE}

Several dimensions of knowledge can be encompassed by the larger conceptual umbrella from which it emerged. More than a generation ago, English and English (1958, pp. 284-285) listed three entries for knowledge labeled as "highly distinct." The first is "simple knowledge," which has three "distinct meanings": simple knowledge that is the act of knowing, also called apprehension; a body of understood information possessed by an individual or culture; and that part of a person's information in accord with established fact." A second highly distinct meaning, "functional knowledge," refers to knowledge that can be applied and used, and yet a third is "knowledge of results," defined as learning facilitated when the learner is informed that a particular response is correct. Parsing out these meanings in today's literature is probably less profitable than noting that their defining invokes terms that lead to some external criterion or verification, e.g., "in accord with established fact." Clearly, with the growth of disciplines and time, the terrain is more complex, and here we pose some suggested distinctions.

\section{PHILOSOPHICAL UNDERPINNINGS}

Before breaking bread with others sharing a social science tradition for investigation and discovery leading to "truth claims," we need to acknowledge the philosophical arguments that have plagued communication over the past couple of decades. Many years ago, when the senior author was enamored with the philosophy of science class at their doctoral program, Tichenor mentioned that this was a "black hole" that could become all-consuming and have debilitating effects on one's productivity. We're paraphrasing his words here, but Tichenor was right. And, while each of the authors have addressed this area off and on, we've generally escaped the black hole, only to see it retard progress in developing what Berger and Chaffee (1987) called "communication science." The philosophical arguments are not new--dating back to Descartes and Kant--notably the effort to "guarantee the reality of the real and the truth of our beliefs in a secular manner, i.e., without recourse to divine instances" (Sanbothe, 2008, p. 94).

One might conclude that internal struggles within communication have concerned less the influence of the divine but more the influence of the humanities. According to the tenets of idealism, reality is the creation of the mind or spirit, and reason itself is a superior source of knowledge; according to realism, objects perceived through our senses exist independently of the mind and universals exist outside the mind, which leads us to rely on "empirical" methods for learning about reality, particularly as it's encapsulated in the subject of this paper, "knowledge."

This debate over realism (vs. anti-realism) can be found in contemporary theories of knowledge. Sandboothe (2008), for instance, provides an extensive discussion of contemporary theory of knowledge. He suggests that there is a stalemate between realism and anti-realism, which "results from the circumstance that the criteria, to which realistic and anti-realistic examination procedures refer, are equally under-determined" (p. 95). While the realists argue about whether, and how, an external domain outside the world of our beliefs can be proven as neutral criteria for their examination, the anti-realists are trying to solve the recourse problem already described by the philosopher Wittgenstein. This problem consists of the fact that the application of constitutive schemes to single cases of concrete beliefs presupposes high-level schemes that rule the application procedures itself. But for them the same application problem obviously arises again and must be solved by using metarules. Thus, "the cycle repeats itself ad-infinitum" (p. 95). One typical response is to surrender to the skeptic, while others argue the need to safeguard the inter-subjective commitment of our linguistic references (Davidson, 2001). Brandom (1994, 2008) maintains that we should "understand the objectivity of the reference much more as an intersubjective commitment upon which we've implicitly agreed in the context of our concrete language use in historically 
and culturally determined social practices" (Sandbothe, 2008, p. 97).

Our textbooks on methodology may include humanistic, historical and social science approaches to discovering "knowledge," but empirical approaches almost always point to the importance of inter-subjectivity, or the agreement among scholars on the "meaning" of our concepts. Cronkhite (1986) is representative of those who long ago suggested that the value of a method will be based on the knowledge it generates, not shrill arguments. Thus, we suggest not letting skepticism and relativity prohibit us from spending time on the concept of "knowledge."

\section{BEYOND THE PHILOSOPHICAL DIVIDE}

First, media consumers do have "scientific knowledge," which certainly includes the "hard laws" of natural sciences. If the television weather forecaster notes that towering cumulus clouds are developing, a viewer's knowledge that such clouds are likely to produce rain showers is a measure of their weather "knowledge," information that is unlikely to change in one's life time (though the actual reliability of that weather prediction is more problematic). Such knowledge might best be viewed as including "settled" knowledge, where a long-term consensus has emerged within the pertinent community of scholars who have "discovered" or "established" the facts involved. There are probably few differences of opinion here, for we're talking about what's taught in science 101, or the version translated for consumption by the general public. Even here, however, the established "knowledge" may be utilized in predictions of the future where there's room for error, leaving us with "beliefs" about what the weather will be tomorrow using available knowledge.

On the frontiers of any particular science, the foundation of knowledge may be too thin (or new) for such a consensus, or may represent a domain where the "facts" are inconsistent or unclear. This might be labeled "emerging scientific knowledge," where the public's given a snapshot and essentially is looking in on the scientific process as it is carried out. This might include the study of the week that reports relationships between life style or the consumption of various foods and the likelihood that one will contract some disease. Within the health area, physicians and other practitioners often give recommendations couched with tentative language, e.g., "from what we know so far, the data seem to indicate..." And many of these studies appear in the media, which some time ago recognized the news value of such research. Clearly, there's a distinction that could be made, as we do in our lectures, between knowledge that is probabilistic and settled facts about physical laws and properties. This entire area deserves further sorting out, not for our students, but for how we study the public's understanding. Since most of what we "learn" as scholars in communication is probabilistic "knowledge," our work falls at best into this category, as "emerging scientific knowledge."

It's on the frontiers of science where we encounter the more controversial issues, particularly those that address the largest questions about the origins of life, the origins of the universe, or the impact of human activity on our environment. These are questions about "large systems." This is a domain in which a consensus may be emerging, as in the case of global warming, but it's also where policy issues and belief systems other than science intrude into the process most heavily.

For years, we told our students that science only tells us what is, whatever the degree of certainty or margin of error, not what ought to be. And the latter is where religion and world views, values and ideology have legitimate claims on the public's attention. And this is where, as Tichenor acknowledged recently, the "knowledge gap" may be about gaps in beliefs about what "we know." However, the distinction between beliefs about what we know and beliefs that express values, what out to be, is important, a distinction that separates the domain of "knowledge" from the domain where we make assessments about how we want our lives to proceed, what we value, and what's acceptable or unacceptable.

We also should expect differences in learning processes, from individual differences to contextual influences and media impact, depending on whether the target "knowledge" is settled scientific processes, emerging scientific knowledge, basic laws/processes or probabilistic relationships, unsettled claims about what "we know," or knowledge about large systems such as the universe or global systems that will be studied beyond any of our life times. The same could be said of scientific knowledge that has generated controversy because of public conflicts stemming from religion, world views or philosophical systems. We can attend to these, but only if we make the distinctions and subject them to empirical study. Differences in knowledge gap studies are likely due to differences in the types of knowledge being studied.

\section{A TAXONOMY OF KNOWLEDGE}

Scholars can study the acquisition of scientific knowledge, but other forms of knowledge may be more important, and we'll consider them here. Political scientists have long measured people's political information; Price's (1999) accounting of scales measuring political information includes measures of political knowledge, political information, political awareness, candidate like/dislike responses, issue awareness, foreign country information and news recall. These scales, and other work (Delli Carpini \& Keeter, 1996), examine what people, or citizens, know about politics, government and public issues.

A recent metanalysis (Hwang \& Jeong, 2009) uncovered a positive correlation between education and level of knowledge $(r=28)$, although the 30 year frame uncovered no differences in the size of the gap (a) over time and (b) between issues of higher and lower publicity. However, the authors (p. 513) noted that "gap magnitude was moderated by topic, setting, knowledge measure, and study design, but not by publication status, country, and sampling method ${ }^{3}$."

Some of this work is rooted in studies focusing on ideological thinking, which is important when the "political" information is constrained by one's thinking, attitudes and opinions. Research also has examined citizen expertise and 
political sophistication. Zaller (1990, p. 125) points out that much confusion surrounds the conceptualization and measurement of political information, and Price (1999, p. 596) suggests that the two terms coming closest to being interchangeable are "information" and "knowledge." Citing Delli Carpini and Keeter (1996), Price (1999, p. 596) suggests that the concept is restricted to "factual knowledge," something objectively verifiable as opposed to beliefs that cannot be verified. Of course, "verification," like beauty, is in the eyes of the beholder for relativists.

Even if we accept this domain restriction, there are dimensions to the concept of knowledge that deserve attention from communication researchers beyond those cited above. Sandvik and Thorhauge (2008) identify four "orders of knowledge": factual knowledge that refers to knowledge about the world; situational knowledge that refers to knowledge about knowledge; systemic knowledge, which is knowledge about the knowledge system; and world knowledge, which refers to collective basis of knowledge. For them "communication research means making obvious the connection between statements about the world and those knowledge systems that provide the statements within their truth-value" (p. 189).

\section{CONFIRMATORY VS. DOMAIN SPECIFIC KNOWLEDGE}

We begin with the confirmatory knowledge of our political and social systems, where people learn about our government (e.g., Althaus \& Tewksbury, 2000), current activities of or actors in the government or public life (Hofstetter et al., 1999; Kleinnijenhuis, 1991), and the content of public actions or legislation (Stamm et al., 1997). Such knowledge is also "settled" at the point of our examination, much like basic scientific processes or laws. Delli Carpini and Keeter (1996) provide a typology for confirmatory knowledge that includes the following elements: the rules of the game, the substance of politics, and people and parties. A content-valid assessment of confirmatory knowledge should encompass these aspects of politics.

But closely linked to such knowledge is that which has no settled referent, better known as domain specific knowledge, e.g., positions on a vague issue such as economic regulation (Drew \& Weaver, 1998; Johnson et al., 1999; Kwak, 1999; McLeod, Guo, Daily, Steele, Huang, Horowitz, Chen, 1996). While we can construct specific and confirmatory knowledge about whether a candidate says s/he will vote for particular legislation, the political process is generally less stable and deliberately open to disagreements, subtle differences and positions to be argued.

Equally volatile is campaign specific information such as candidate's issue stance, campaign endorsements, and candidate's image (e.g., Drew \& Weaver, 2004; Tan, 1980). Here too we would expect the public's acquisition of knowledge to differ, depending on whether the target is "settled" (where all the pertinent actors agree on the facts), simple or complex. All too often, ideology compounds the fluidity of domain specific knowledge. Thus, we can make conceptual distinctions that could enhance our understanding of how the public learns from the media if we subject them to empirical examination.

\section{KNOWLEDGE OF PUBLIC AFFAIRS}

The second domain of interest involves knowledge about public affairs news, what's happening in the world, the hard news content of our newspapers, newscasts and many websites. Such public affairs knowledge has figured prominently in studies of the knowledge gap (Drew \& Weaver, 1990; Price \& Zaller; 1993; Tewksbury, Weaver, \& Maddex, 2001). In fact, as Gaziano and Gaziano (1996) pointed out, the knowledge gap hypothesis rests upon an assumption that public affairs and science news have a general appeal such that gaps are more likely to emerge from these two domains (Bryant \& Miron, 2004). The theory itself was premised in part on differences in message processing skills, the utility of such knowledge for interpersonal communication (are these the types of things you discuss with friends?), levels of interest in such affairs, and the importance of such content to each of the media (particularly print). While some of these factors may be relevant for gaps based on public affairs, others are more important for gaps based on knowledge about science, health or the political or social system (e.g., Chew \& Palmer, 1994; Finnegan, Viswanath, Kahn, \& Hannan, 1993; Wanta \& Elliot, 1995).

\section{RELATIONAL VS. PIECEWISE KNOWLEDGE}

The third domain is a form that might be called "relational knowledge," which presumes one can compare how close a political position held by a candidate is to their position. Moore (1987) took this approach in a knowledge gap study where he called the dependent variable "objective knowledge," the accuracy with which voters could identify which candidate was closer to them on two issues. Relational knowledge taps knowledge holding at a higher level than piecewise accumulation of facts. The distinction between relational and piecewise knowledge is important because common to public opinion surveys is the inclusion of isolated factual questions (Neuman, 1981; Zaller, 1992), which may be inadequate in gauging differences in knowledge holding. Along this similar line of reasoning is the distinction between awareness and sophistication (Levendusky \& Jackman, 2003). In essence, it is critical to ask how well a piece of information is stored and processed.

\section{HEURISTICS}

The distinction between awareness and sophistication enables us to realize that not every piece of information or knowledge is schematically integrated. For instance, American voters have been consistently shown to have scanty knowledge about politics and perform poorly on tests of civics and public affairs knowledge (Delli Carpini \& Keeter, 1996). Nevertheless, American representative democracy seems to work reasonably well with an illinformed public. This apparent paradox prompted political scientists to propose that voters rely on cognitive heuristics to make political decisions (Lau \& Redlawsk, 2001; Kuklinski \& Quirk, 1998; Lupia, 1994; Popkin, 1991). Cognitive heuristics refer to information shortcuts that 
enable reasonable decision making with minimal amount of cognitive processing (Fisk \& Taylor, 1984). In the absence of factual information, individuals can utilize cognitive shortcuts or heuristics to guide their political decision making. The distinction between heuristics and other conceptualizations of knowledge is meaningful because political knowledge is not always a product of active information seeking (Popkin, 1991).

\section{CULTURAL KNOWLEDGE}

Another form of knowledge focuses on domains where the knowledge is not based scientific knowledge claims or reports of activities in the political/public arena. These certainly would include knowledge of our culture and others' cultures. While some of this occurs through formal education, we also learn a lot about other religions and the customs of people from different lands through the media, and the basis for this knowledge is a matter of accuracy (What do Hindu's believe? How do Filipinos celebrate Easter?). Certainly individual differences and levels of interest that account for gaps in knowledge about public affairs would also play an important role here, but media/channel differences could be even more important.

\section{TECHNOLOGY-BASED KNOWLEDGE}

In addition to culture, technology itself represents an area of understanding that deserves our attention every bit as much as science in general. Technology is sometimes viewed as the practical application of scientific knowledge, but it also can be viewed as the human ability to control our environment. Just as much scientific knowledge can be complex and reside beyond the reach of the general public, so too can much technological information. This knowledge can be viewed with many distinctions similar to science, but perhaps our studies should focus on knowledge about technology and technological systems that have immediate impact on people's daily lives, from digital television to the Internet (see Jeffres, Neuendorf, \& Atkin, 2003; Bucy, Gantz, \& Wang, 2007). Clearly, we would expect such individual differences as age and education to play prominent roles in understanding technological knowledge gaps (e.g., Lin, Salwen, \& Abdulla, 2005).

In fact, these and other demographic artifacts of technology adoption could well compound the kinds of knowledge gaps that observers see defining larger digital divides accompanying media adoption (e.g., Lin \& Atkin, 2007; Salwen, 2005). Bucy et al., (2007), for instance, profiled the competition for print newspapers arising from cable news outlets, broadcast news and online news and blog cites that collectively contribute to a 24-hour news cycle. Lasica (2002) coined the phrase Daily Me in reference to the increasing personalization of news emerging from the long tail of new media. News junkies can now "tailor and filter" news on their home page to suit their own tastes (Bucy, et al., 2007).

These differential knowledge bases could generate corollary influences on audience believes and even involvement, possibly even fragmenting the electorate into "small groups of like-minded individuals who do not interact with other groups or with society as a whole and chose to receive only the news and information that reinforces their beliefs and values" (p. 24)." Thus, despite longstanding relations between traditional media use, knowledge gain and community involvement (e.g., Gaziano, 1997), preliminary work on Internet news consumption (e.g., Nowak, Hamilton, Atkin, \& Rauh, 2010) uncovers inverse linkages between new media use and political knowledge, involvement and the like. In light of this digital news consumption dynamic, continued audience fragmentation may well hasten audience isolation and erode social capital (Putnam, 1995), sense of community, and perhaps even political involvement (see Salwen, Garrison, \& Driscoll, 2005).

\section{COMMUNITY-RELATED KNOWLEDGE}

Another distinction of interest focuses on knowledge of our communities, our neighborhoods, and our immediate environment. Excluding public issues, it is ironic that mass communication scholars have focused so little on the community, the subject of much news in our papers and the context where people act out their daily lives. We ask people about activities of our public officials, the national unemployment rate, and policy initiatives in the Middle East, but we neglect to ask about what people know about their communities. At a time when many bemoan the "loss of community" and the need to revitalize our cities and pay attention to our physical environment, we should examine how people learn (or fail to learn) about their communities, what they know, and how gaps occur depending on one's status, tenure and interest.

Earlier knowledge gap studies showed that conflict within the community led to decline in knowledge gaps based on social status (e.g., Gaziano, 1997). With the shrinking of newspaper content and the virtual demise of local radio news, who's paying attention to local institutions (from cultural organizations and foundations to community development organizations and major employers) and is the fragmented audience leading to serious knowledge gaps that support quite different images of the community, its problems and what policy makers should do? Very few studies have asked any questions about communities outside of political activities (for an exception, see Jeffres, Neuendorf, \& Atkin, 2003).

Media accounts and faculty conversations often convey our students' superior knowledge of popular culture, e.g., what Brittany Spears is doing or who won American Idol, vs. their nodding acquaintance with even recent history and serious public affairs. And, while any gaps about popular culture may seem at first blush to be less significant for our study, they're more than trivial, because such information feeds into people's images and beliefs about other people and other places. Potter (2003) suggests that seniors are more vulnerable to cultivation effects about crime based on their reduced mobility and fears and exposure to certain media messages. Might we not also expect similar gaps in information about popular figures and activities to have similar differential effects on public perceptions about policies toward cultural groups (e.g., young people, gays) or regions (e.g., the South or Northeast)? 
It seems reasonable to expect that our "knowledge" about "what people know" will improve with conceptualizations that make the kinds of distinctions raised here.

We also need to link the message, or information processing literature and how we store knowledge to our conceptualizations of knowledge. This has already begun in the political campaign literature, where Eveland and his associates have invoked the concept of "knowledge structure density" as a measure of the interconnectedness of a particular domain within one's cognitive network, i.e., how issues are related in citizens' thinking about politics (see Eveland \& Hively, 2006, 2009).

Tichenor and his colleagues posed the knowledge gap at the community level, but they cited several "contributory reasons why the knowledge gap should appear and widen with increasing levels of media input" (Tichenor, et al., 1970, pp. 161-162). This encompasses communication skills, stored information, relevant social contact, the media system that delivers messages, and selective exposure, acceptance and retention of information. The last of these is a reference to people's information or message processing, and, although this takes us to a different level, it's a useful addition to an effort to integrate literatures in a discipline that crosses levels from sociology/society to the individual/psychology.

And a substantial literature with relevant concepts exists. For example, bottom-up and top-down processing are important variables. When features of the message or environment are paramount, the larger dynamic is called bottom-up processing; when memory and cognition become influential, that would be a case of top-down processing. Although somewhat less popular recently, the concepts of schema and frames have informed considerable literature, but with a focus on opinions rather than knowledge. Theories of human memory also are helpful, and the applications have occurred in the media effects literature, where we look at semantic memory, working memory, and other concepts (see Jeffres, 1994, pp. 283-324, for an application in media message processing).

The journal in which much of this research corpus resides is titled Communication Theory. But a good portion of the articles residing in that forum address philosophical differences, ideologies, and meta-theoretical perspectives rather than advancing social science theories or considering how our concepts describe and map the landscape that represents communication phenomena today. In addition, communication scholars following the social science tradition seldom return to the conceptual roots of the 1970s, when we engaged in concept explications and tested wide ranging possibilities.

\section{CONCLUSION}

In sum, the knowledge gap has a long and illustrious history, morphing at one point into an "effects gap" (Rogers, 1976). But even our most ambitious reviews of the literature have generally focused on other aspects of the theory rather than questioning the nature of the central concept, knowledge. Yet the knowledge gap may prove to be an important theory describing current phenomena if we apply it in an environment where distinctions between modes of communication have blurred, where individual choice and control have increased greatly, and generational differences have become more pronounced.

This essay has argued for moving beyond the "relativistic" arguments and considering how the concepts and the theory may be useful in describing reality today. We've focused on only one concept here, but this represents a foundation upon which later work can build. In particular, later work should explore the extent to which younger voters, the vanguard of the digital generation, use new media channels to acquire news and the impact that these tailored outlets have on knowledge gaps.

\section{ENDNOTES}

${ }^{1}$ In fact, emerging wired and wireless channels are ushering in a \$4 trillion "I.C.E." (information, communication and entertainment) age (Pelton, cited in Lin \& Atkin, 2007).

${ }^{2}$ An interesting, recent article describes an experiment on political knowledge estimation that's pertinent to the method employed by Tichenor and his colleagues much earlier (Miller \& Orr, 2008).

${ }^{3}$ Hwang and Jeong (2009, p. 513) also conclude that “...smaller gaps were found for (a) health-science topics compared to social-political topics and (b) local/personal issues compared to international issues."

\section{REFERENCES}

Berger, C.R., \& Chaffee, S.H. Chaffee (Eds.) (1987). Handbook of Communication Science. Newbury Park, CA: Sage Publications.

Brandom, R. (2008). Between saying and doing. Towards an analytic pragmatism. Oxford: Oxford University Press.

Brandom, R. (1994). Making it explicit. Reasoning, representing and discursive commitment. Cambridge: Harvard University Press.

Bryant, J., \& Miron, D. (2004). Theory and research in mass communication. Journal of Communication, 54, 662-704.

Bucy, E.P., Gantz, W., \& Wang, Z. (2007). Media technology and the 24hour news cycle. In C. A. Lin \& D.J. Atkin (Eds.), Communication Technology and Social Change: Theory and Implications. Mahwah, NJ: Lawrence Erlbaum Associates.

Chew, F., \& Palmer, S. (1994). Interest, the knowledge gap, and televised programming. Journal of Broadcasting \& Electronic Media, 38, 271-287.

Cronkhite, G. (1986). On the focus, scope and coherence of the study of human symbolic activity. The Quarterly Journal of Speech, 72, 231-246.

Davison, D. (2001). Subjective, intersubjective, objective. Oxford: Clarendon Press.

Delli Carpini, M.X., \& Keeter, S. (1996). What Americans know about politics and why it matters. New Haven, CT: Yale University Press.

Donohue, G.A., Tichenor, P.J., \& Olien, C.N. (1973a). Mass media functions, knowledge and social control. Journalism Quarterly, 50, $652-659$.

Donohue, G.A., Tichenor, P.J., \& Olien, C.N. (1973b). Mass media and the knowledge gap. Communication Research, 2, 3-23.

Donohue, G.A., Tichenor, P.J., \& Olien, C.N. (1975). Mass media and the knowledge gap: A hypothesis reconsidered. Communication Research, 2, 3-23.

Drew, D., \& Weaver, D. (1990). Media attention, media exposure and media effect. Journalism and Mass Communication Quarterly, 67, 4, 740748.

Drew, D., \& Weaver, D. (1991). Voter learning in the 1988 presidential election: Did the debates and the media matter? Journalism and Mass Communication Quarterly, 68, 1/2, 27-37. 
Drew, D., \& Weaver, D. (1998). Voter learning in the 1996 presidential election: Did the media matter?" Journalism and Mass Communication Quarterly, 75, 292-301.

English, H.B., \& English, A.C. (1958). A comprehensive dictionary of psychological and psychoanalytical terms. NY: David McKay Co.

Eveland, W. P. Jr. (2004). The effect of political discussion in producing informed citizens: The roles of information, motivation and elaboration. Political Communication, 21, 177-193.

Eveland, W.P. Jr., \& Hively, M.H. (2006). Political discussion frequency, network size, and "heterogeneity" of discussion as predictors of political knowledge and participation. Paper presented at the annual meeting of the Midwest Association for Public Opinion Research, Chicago, IL.

Eveland, W. P., \& Hively, M. H. (2009). Political discussion frequency, network size, and "heterogeneity" of discussion as predictors of political knowledge and political participation. Journal of Communication, 59, 205-224.

Eveland, W.P. Jr., \& Scheufele, D.A. (2000). Connecting news media use with gaps in knowledge and participation. Political Communication, 17, 215-237.

Finnegan Jr., J. R., Visawnath, K., Kahn, E., \& Hannan, P. (1993). Exposure to the sources of heart disease prevention information: Community type and social group differences," Journalism Quarterly, 70, 569584.

Fiske, S.T. \& Taylor, S.E. (1984). Social Cognition. NY: Random House.

Gallagher, R. (2007). Does knowledge of ethics and end-of-life issues inform choices in advance care planning scenarios? Journal of the American Geriatrics Society, 55, 1695-1696.

Gaziano, C. (1997). Forecast 2000: Widening knowledge gaps. Journalism \& Mass Communication Quarterly, 74, 237-264.

Genova, B.K.L., \& Greenberg, B.S. (1979). Interest in news and the knowledge gap. Public Opinion Quarterly, 43, 79-91.

Griffin, R. J. (1990). Energy in the eighties: Education, communication and the knowledge gap. Journalism Quarterly, 67, 554-566.

Holbrook, T.M. (2002). Presidential campaigns and the knowledge gap. Political Communication, 19, 437-454.

Hwang \& Jeong (2009). Revisiting the knowledge gap hypothesis: A metaAnalysis of 35 years of research. Journalism and Mass Communication Quarterly, 86 (3), 513-532.

Jeffres, L.W., Neuendorf, K., \& Atkin, D. (2003). Knowledge Gaps in the Internet Age. Paper presented to the Communication \& Technology Division at the annual conference of the International Communication Association, San Diego, Calif., May, 2003.

Jeffres, Neuendorf, \& Atkin, D. (2003, May). Knowledge gaps in the Internet age. Paper presented at the International Communication Association, San Diego.

Kleinnijenhuis, J. (1991). Newspaper complexity and the knowledge gap. European Journal of Communication, 6, 499-522.

Kuklinski, J.H., \& Quirk, P.J. (2000). Reconsidering the rational public: Cognition,heuristics, and mass opinion. In A. Lupia, M. D. McCubbins, \& S. L. Popkin (Eds.). Elements of reason: Cognition, choice, and the bounds of rationality (pp. 153 - 182). New York: Cambridge University Press.

Kwak, N. (1999). Revisiting the knowledge gap hypothesis: Education, motivation and media use, Communication Research, 26, 385-413.

Lasica, J.D. (2002). The promise of the Daily Me. Online Journalism Review. Retrieved March 28, 2006 from http://www.ojr.org/ojr/technology/1017778824.php.

Lau, R. R., \& Redlawsk, D. P. (2001). Advantages and disadvantages of cognitive heuristics in political decision making. American Journal of Political Science, 45, 951-971.

Lee, G., \& Cappella, J. N. (2001). The effects of political talk radio on political attitude formation: Exposure versus knowledge. Political Communication, 18, 369-394.

Lin, Salwen, \& Abdulla (2005). Uses and gratification of online and offline news: new wine in an old bottle? In M.B. Salwen, B. Garrison, \& P.D. Driscoll (Eds.), Online News and the Public (pp. 221-236). Mahwah, NJ: Lawrence Erlbaum Associates.

Lin \& Atkin (2007). Communication technology and social change. New York: Routledge.

Liu, Y-I., \& Eveland, W.P. Jr. (2005). Education, need for cognition, and campaign interest as moderators of news effects on political knowledge: An analysis of the knowledge gap. Journalism \& Mass Communication Quarterly, 82, 910-929.
Lupia, A. (1994). Shortcuts versus encyclopedias: Information and voting behavior in California insurance reform elections. American Political Science Review, 88, 63-76.

McCann, J.A., \& Lawson, C. (2006). Presidential campaigns and the knowledge gap in three transitional democracies. Political Research Quarterly, 59, 13-22.

McLeod, J. M., Guo, Z., Daily, K., Steele, C. A., Huang, H., Horowitz, E., \& Chen, H. (1996). The impact of traditional and nontraditional media forms in the 1992 presidential election. Journalism \& Mass Communication Quarterly, 73, 401-416.

Meirick, P.C., \& Wackman, D.B. (2004). Kids voting and political knowledge, Social Science Quarterly, 85, 1161-1177.

Miller, M.K., \& Orr, S.K. (2008). Experimenting with a "third way" in political knowledge estimation, Public Opinion Quarterly, 72, 768780.

Moore, D.W. (1987). Political campaigns and the knowledge-gap hypothesis. Public Opinion Quarterly, 51, 186-200.

Niederdeppe, J. (2008). Beyond knowledge gaps: Examining socioeconomic differences in response to cancer news, Human Communication Research, 34, 423-447.

Nowak, et al. (2010). The effect of exposure to new and traditional media on political orienting among college students. American Journal of Media Psychology, 2 (online).

Pavlik, J. V., \& McIntosh, S. (2004). Converging media: An introduction to Mass Communication. Boston, NY: Allyn \& Bacon.

Popkin, S. (1994). The reasoning voter. University of Chicago Press.

Potter, W.J. (2003). The 11 myths of media violence. Thousand Oaks, Calif.: Sage Publications.

Price, V. (1999). Political information. In J.P. Robinson, P.R. Shaver \& L.S. Wrightsman (eds.). Measures of political attitudes (pp. 591-639) San Diego, CA: Academic Press.

Price, V., \& Zaller, J. (1993). Who gets the news? Alternative measures of news reception and their implications for research. Public Opinion Quarterly, 57, 133-164.

Rhine, S.L., Bennett, S.E., \& Flickinger, R.S. (2001). Gaps in Americans' knowledge about the Bosnian civil war, American Politics Research, 29, 592-607.

Rogers, E. (1976). New perspectives on communication and development, Communication Research, 3, 99-106.

Rucinski, D. (2004). Community boundedness, personal relevance, and the knowledge gap. Communication Research, 31, 472-495.

Salwen (2005). Online News Trends. In M.B. Salwen, B. Garrison, \& P.D.

Driscoll (Eds.), Online News and the Public (pp. 47-79). Mahwah, NJ: Lawrence Erlbaum Associates.

Salwen et al. (2005). (Eds.), Online News and the Public. Mahwah, NJ: Lawrence Erlbaum Associates.

Sandbothe, M. (2008). Media and knowledge: Some pragmatist remarks about media philosophy within and beyond the limits of epistemology, Nordicom Review, 29, 93-101.

Scheufele, D.A., Nisbet, M.C., Brossard, D., \& Nisbet, E.C. (2004). Social structure and citizenship: Examining the impacts of social setting, network heterogeneity, and informational variables on political participation. Political Communication, 21, 315-338.

Stamm, K.R. \& Weis, R. (1986). The newspaper and community integration: A study of ties to a local church community. Communication Research, 13, 125-137.

Tichenor, P.J., Donohue, G.A., \& Olien, C.N. (1970). Mass media flow and differential growth in knowledge," Public Opinion Quarterly, 34, 159-170.

Tichenor, P.J., Olien, C.N., \& Donohue, G.A. (1987). Effect of use of metro dailies on knowledge gap in small towns. Journalism Quarterly, 64, 329-336.

Tewksbury, D., Weaver, A.J., \& Maddex, B.D. (2001). Accidentally informed: Incidental news exposure on the World Wide Web. Journalism \& Mass Communication Quarterly, 78, 533-554.

Valente, T.W., \& Saba, W.P. (2001). Campaign exposure and interpersonal communication as factors in contraceptive use in Bolivia. Journal of Health Communication, 6, 303-322.

Viswanath, K., \& Finnegan, J. R. Jr. (1996). The knowledge gap hypothesis: Twenty years later. In B. R. Burleson \& A. W. Kunkel (Eds.). Communication Yearbook Volume 19 (pp. 187-227). Thousand Oaks, CA: Sage Publications.

Viswanath, K., Finnegan, J.R. Jr., Hannan, P.J., \& Luepker, R.V. (1991). Health and knowledge gaps: Some lessons from the Minnesota Heart Health Program. American Behavioral Scientist, 34, 712-726. 
Wanta, W. \& Elliott, W. R. (1995). Did the "Magic" Work? Knowledge of HIV/AIDS and the Knowledge Gap Hypothesis. Journalism and Mass Communication Quarterly, 72, 312-321.

Weaver, D., \& Drew, D. (2001). Voter learning and interest in the 2000 presidential election: Did the media matter? Journalism and Mass Communication Quarterly, 78, 787-798.

Weaver, D., \& Drew, D. (1995). Voter learning in the 1992 presidential election: did the "nontraditional" media and debates matter? Journalism \& Mass Communication Quarterly, 72, 7-17.
Weaver, D., \& Drew, D. (1993). Voter learning in the 1990 election: Did the media come through? Journalism and Mass Communication Quarterly, 70,356-368.

Weenig, M.W.H., \& Midden, C.J.H. (1997). Mass-media information campaigns and knowledge-gap effects, Journal of Applied Social Psychology, 27, 945-958.

Zaller, J. (1990). Political awareness, elite opinion leadership, and the mass survey response. Social Cognition, 8, 125-153.

Received: August 05, 2011

(C) Jeffres et al..; Licensee Bentham Open.

This is an open access article licensed under the terms of the Creative Commons Attribution Non-Commercial License (http://creativecommons.org/licenses/by-nc/3.0/) which permits unrestricted, non-commercial use, distribution and reproduction in any medium, provided the work is properly cited. 